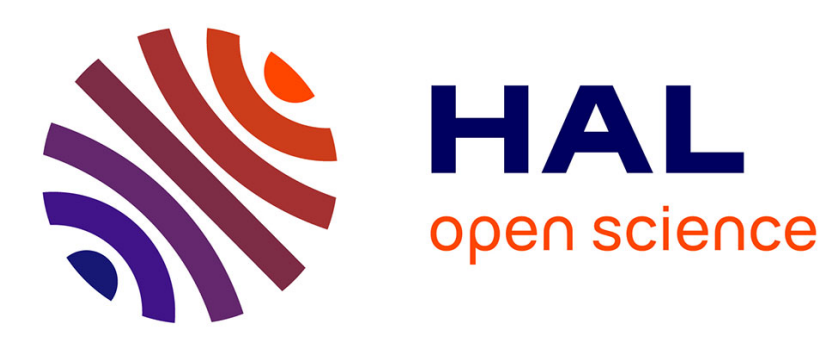

\title{
About Lewis's heritage: chemical interpretations and quantum chemistry
}

\author{
Bernard Silvi
}

\section{To cite this version:}

Bernard Silvi. About Lewis's heritage: chemical interpretations and quantum chemistry. Theoretical Chemistry Accounts: Theory, Computation, and Modeling, 2017, 136 (9), pp.106. 10.1007/s00214017-2146-3 . hal-01614711

\section{HAL Id: hal-01614711 https: / hal.sorbonne-universite.fr/hal-01614711}

Submitted on 11 Oct 2017

HAL is a multi-disciplinary open access archive for the deposit and dissemination of scientific research documents, whether they are published or not. The documents may come from teaching and research institutions in France or abroad, or from public or private research centers.
L'archive ouverte pluridisciplinaire HAL, est destinée au dépôt et à la diffusion de documents scientifiques de niveau recherche, publiés ou non, émanant des établissements d'enseignement et de recherche français ou étrangers, des laboratoires publics ou privés. 


\title{
About Lewis's heritage: chemical interpretations and quantum chemistry
}

\author{
Bernard Silvi ${ }^{1}$
}

\begin{abstract}
Some of the opinions I have on the description of the structure of the matter in chemistry.
\end{abstract}

Keywords Representation of the matter - Lewis's model · VSEPR · Epistemology

\section{Importance of chemical explanations}

One of the aim of Chemistry as a science is to study and explain the structure of the matter and its transformations. In general, Science has to tell how and why a given phenomenon occurs in given circumstances. In principle, explanations are not essentially communicative and exist independently of the intention of explaining anything to anyone. However, the availability of different levels of explanation is essential for the transmission of knowledge and therefore for the development of scientific ideas. To illustrate the diversity of explanations let me use an example borrowed from Del Re [1]. To the question why are most glass bottles green? A technologist will answer "because the cost of their production is low, a physicist will invoke a selective absorption of light whereas a chemist will say that ordinary glass contains ferrous ions." In this example several causal processes have been invoked to explain the same fact. These are brief and concise answers, all can be validated or rejected. They are

Published as part of the special collection of articles "First European Symposium on Chemical Bonding".

Bernard Silvi

silvi@1ct.jussieu.fr

1 UPMC, Univ Paris 06, UMR 7616, Laboratoire de Chimie Théorique, Sorbonne Universités, Case courrier 137, 4 place Jussieu, 75005 Paris, France complementary because each of them partially addresses the question. However, other answers can be given. For instance, one can object that bottles being made to store liquid food (wine, beer), coloured glass is chosen mostly because it prevents sunlight to downgrade the antioxidants and therefore increases the storage life. ${ }^{1}$ The answer given by the chemist explicitly invokes the chemical composition of the glass used to make bottles and for this reason it should be referred to as a chemical explanation.

Chemical explanations are grounded on the knowledge of Chemistry. Chemical explanations of the structure of the matter rely on a picture in which elemental atoms are linked by bonds. Bonding interactions are moreover ruled by the location of the constituting elements in the periodic table. Chemical explanations often make use concepts proper to Chemistry, such as those of bond, lone pair, valence,..., which have been criticized as lacking of scientific content or have not enough precise or inconsistent definitions. (cf. R. Thom in Paraboles et Catastrophes [2]), We are often faced to a demarcation problem: to what extend chemical explanations are scientific explanations or in other words what are the requirements which must be fulfilled to make a chemical explanation a scientific explanation. Therefore, explanations have to be critically analysed from different epistemological viewpoints such as Duhemian conventionalism and methodological falsificationism. We must also be conscious that chemical explanations may have different structures: for example the occurrence of an event can be deduced from a set of true

\footnotetext{
${ }^{1}$ Ordinary soda-lime glass appears colourless when it is thin. Iron oxide impurities produce a green tint which can be viewed by the naked eye for thick pieces. In the case of green bottle iron(II) oxide is added during the production process.
} 
propositions involving at least a scientific law or principle like in the deductive-nomological account [3], from a theory that unifies many phenomena (unification account $[4,5]$ ) or by tracing the causal processes and interactions leading to the event (causal model [6]). For example the chemical explanation of the equilibrium geometry of a molecule by the VSEPR rules belongs to the deductivenomological since it requires on the one hand the knowledge of number of valence electrons of the constitutive element atoms which forms a set of true propositions and on the other hand a set of phenomenological rules one may consider as scientific laws. An answer of the unification account, which is no longer a chemical explanation, would be that the equilibrium geometry of a molecule corresponds to the absolute minimum of the Born-Oppenheimer energy surface.

Quantum Chemistry has played and will continue to play an important role in the design of explanations. In addition to strictly chemical explanations it is convenient consider quantum chemical explanations which are rooted on the interpretation of the variational calculus yielding approximate expressions of the many-body wave function. Quantum chemical explanations uses concepts such as those of orbitals, configurations, valence-bond structures which appear as mathematical intermediates enabling the approximate resolution of the many-body Schrödinger equation. In this context a physical significance is given to non-referring quantities yielding epistemological difficulties as pointed out by Coulson [7]. As pointed out by Scerri [8], "orbitals and the related concept of electronic configurations, neither of which truly "exist" in many-electron atoms according to a strict interpretation of quantum mechanics, have become the central paradigm at all levels of chemistry." Although a majority of chemists consider Quantum chemical explanations as a subpart of chemical explanations, I think useful to keep the distinction. In fact, the very nature of quantum chemical explanations hampers by construction their falsification by computational chemistry numerical experiments which is not the case of purely chemical explanations.

\section{The representation of the matter}

We know for almost a century that the matter is made of particles. These particles have very small "classical" sizes. For example the classical radii of electrons, neutron and protons are

1. Electron: $10^{-18} \mathrm{~m}$

2. Proton and neutron: $1.75 \times 10^{-15} \mathrm{~m}$

3. The size of nuclei ranges from $1.75 \times 10^{-15} \mathrm{~m}(\mathrm{H})$ to $15 \times$ $10^{-15} \mathrm{~m}(\mathrm{U})$
Compared to atoms radii, $3 \times 10^{-11} \mathrm{~m}(\mathrm{He})$ to $3 \times 10^{-11}$ $\mathrm{m}(\mathrm{Cs})$, we realize that almost the whole volume of an atom, and a fortiori, of a molecule is occupied by vacuum. Another point is that the size of electrons and nuclei prevents their direct observation with an ideal microscope, the Abbe relation would imply a wavelength such as the energy of each photon should be about one million times larger than the loss of mass energy of the fusion of two deuterium nuclei into a tritium nucleus and a proton in the case of electrons and "only" one hundred times larger for a heavy element nucleus. Fortunately, electron and nuclei do not behave classically, they are ruled by the laws of Quantum Mechanics. A consequence is that they cannot be directly observed, instead we have access to their footprints:

An individual quantum object is intuitively given to an observer only by the actual isolated footprints it leaves in the perceptual world of the laboratory, the record of individual measurements. It is not just a conceptual object, nor is it an "embodied object in its own right". It is, however, physical and material because of the footprints it makes in the world. It seems then to exist and function ontologically prior to and some way independently of the phenomenological constitution of classically scientific laboratory space-time.

I found these sentences in the article, Paradoxes of Measurement [9], published by Patrick A. Heelan in 2003. Scientists are like the prisoners of Plato's cave allegory, they are warned that the shadows on the wall is not the reality they are looking for but clues from which they have to construct the most plausible story. In this respect the identification and the deciphering of footprints are essential.

Cultural background is decisive to carry out this task successfully. It had been recently illustrated by a recent archaeological study in which a morpho-classificatory approach has been used to decipher human footprints from the Ice Age of 17,000 years ago preserved in painted caves of the south of France [10]. The footprints have been examined and interpreted by three indigenous hunters/trackers from Kalahari who discovered marks unseen in previous archaeological investigations and who were able to determine the number of the prehistoric cave visitors, the sex of each individual and an estimate of his age. Moreover, they proposed very plausible hypothesis on the activity at the origin of the footprints differing from former interpretations made by archaeologists in terms of " ritual dances" or ceremonial behaviour. The example of the footprints found in the Tuc d'Audubert cave is illustrative. Here the San trackers have been able to identify the footprints of two people, a man and a 14-year boy who 
carried clay from a pit to build representation of buffaloes. It illustrates a remark made by Lewis: "In the snobbery of science each branch attempts to rise in the social scale by imitating the methods of the next higher science and by ignoring the methods and phenomena of the sciences beneath" [11].

The footprints of the corpuscular structure of the matter have been found in the results of the early analytical chemistry which led to the formulation of the laws of conservation of mass, of definite proportions and of multiple proportions. This latter involving integers or rational numbers is a strong support for the atomistic (discontinuous) theory which has been reformulated by John Dalton on this indirect experimental basis. Dalton explained the cohesion of the matter by the presence of caloric forces between bonded atoms. It rapidly appeared to Berzélius that electric rather than caloric forces were accountable for the bonding, this idea was further reformulated by Laming in a fully atomistic fashion accounting for Faraday's electrochemical equivalent. Laming's hypotheses introduces atoms of electricity half a century before Joseph John Thomson's discovery of the electron and anticipate the atomic electronic shell structure introduced in the years preceding world war I by Charles $\mathrm{G}$. Barkla and Henry G-J. Moseley:

"A mass of electrical matter, or electricity, may be regarded as composed of electrical atoms, just as a mass of ordinary matter contains ordinary atoms; and thus the sphere of electricity which surrounds an ordinary atom will consist of a number of electrical atoms arranged in concentric strata. The number of electrical atoms belonging to a given ordinary atom may be assumed to be such as to complete its external spherical stratum, or, on the contrary, it may be such as to leave that external spherical stratum more or less imperfect, belonging to a given ordinary atom may be assumed to be such as to complete its external spherical stratum, or, on the contrary, it may be such as to leave that external spherical stratum more or less imperfect." [12]

The atom of electricity was further called "electron" by G. J. Stoney who proposed an estimate of its charge $\left(10^{-19} \mathrm{C}\right)$ on the basis of the electrolysis of water [13]. Other footprints based on stoichiometry led Frankland and Kolbe to introduce the concept of valence which gives a rationale to the bonding connectivity between atoms. It has been an important step ahead in the development of structural chemistry where the important contributions of Kekulé, Kolbe, Couper, Butlerov, Lodschmidt, Crum Brown, Hofmann, Le Bel and Van't Hoff yield the contemporary representations in terms of structural molecular formulas. The emerging picture of a molecule is that of a discrete network where the nodes are occupied by the elemental atoms. The connecting lines represent chemical bonds. The removal of a bond line either increases the number of species by one or opens at least a cycle. The possible valences of the elements are given by their position in the periodic table pioneered by Döbereiner, Béguyer de Chancourtois, Newland and put in its contemporary form by Mendeleev and Lothar Meyer. In this respect, the determination of the structural formulas of the possible isomers corresponding to a given stoichiometry appears to be first a discrete topology problem (before being a geometry problem for the particular case of stereoisomers), which can be mathematically formalized within the framework of finite graph theory [14]. Structural formulas do not intend to provide a pictorial representation of the matter at the atomic scale but rather must be understood as tools condensing in important part of the chemical information on the molecules.

At the end of the XIXth century additional pieces of information were available from physics with the experimental evidence of the electron [15] enabling Lewis to propose a first draft in his 1902 memorandum. It is important to note that Lewis's cubic atoms anticipate Kossel's representation published 14 years later. A few years before the discovery of the nucleus by Rutherford [16], physicists as Thomson [17] and Stark [18] proposed models for molecules which appear nowadays very far from the contemporary conception.

In April 1916, the Journal of the American Chemical Society published the article of Gilbert Newton Lewis entitled as "The atom and the molecule" in which Lewis described his model of chemical bonding emphasizing the role of electron pairs [19]. The electron pair is a fundamental concept in Chemistry which plays a key role in chemical explanations. The model exploits the idea of cubic atoms to built a model in which bonded atoms share edges or faces and is based on six postulates. Lewis emphasizes the importance of the group of two electrons. In fact Lewis had implicitly identified the footprint of the electron spin [20-23] and of the Pauli repulsion [24].

The Lewis's model was further complemented by Ingold with the concept of mesomery $[25,26]$ which accounts for the possibility of a superposition of Lewis's structures, such as in the case of benzene. Langmuir [27], Sidgwick [28], Bury [29] and Blanchard [30] introduced generalizations of the octet rule enabling transition metal atoms to have more than 8 electrons in their valence shell. Alternatively, the octet has been replaced by Linett by a double quartet [31, 32] in order to implicitly introduce the Hund's rule in the building of the structures. The spatial extension of the bonding and non-bonding pairs has been addressed in the model of Sidgwick and Powell [33] where shared and unshared Lewis's electron pairs have the same size inspiring the Valence Shell Electron Pair Repulsion (VSEPR) model of Nyholm and Gillespie [34-37]. 
A first emerging representation of the matter, shared by physicists and chemists, is that of an assembly of nuclei and electrons, bearing, respectively, positive and negative charges, and which mutually interact electrostatically. This is the picture adopted in quantum mechanics to write molecular or crystalline hamiltonians. Chemistry is provided by the atomic number $Z_{A}$ which determine the electron-nucleus and nucleus-nucleus potentials, in other words the external potential in the Density Functional Theory (DFT) formalism. The conjunction of this universal statement with the definition of a free atom or ion, i.e. a nucleus of atomic number $Z$ interacting with $Z \pm q$ electrons yields the current picture of chemistry: matter is made of atoms linked by bonds. In this sentence the word "atom" has lost a precise definition: whereas the set of atomic number is known the number of electrons assigned to each nucleus remains undefined, moreover "bond" has to be defined. In fact, the definitions of "atom in molecule" and of "bond" are correlated. The picture proposed by the Lewis and VSEPR theories is rather that of nuclei surrounded by atomic core and valence shells, the latter gathering bonding and non-bonding electron pairs.

\section{Testing the hypotheses of the Lewis's and VSEPR models with quantum chemical tools}

The Lewis's and VSEPR models provide clear and efficient chemical explanations of the molecular structure. They astonishingly work well and only few systems, such as biradicals, falsify their predictions. The Lewis's model relies on two main hypotheses:

1. The separation of the electrons of an atom into core and valence groups,

2. The distribution of the valence electrons in "Lewis shells" [38] gathering bonding and non-bonding electron pairs around a given atomic core and satisfying magic number rules

The VSEPR model is set of rules giving the geometrical arrangement of the bonding and non-bonding pair domains of each the Lewis shell.

In brief both models assume electrons spatially distributed into groups. Is it possible to identify such groups experimentally or theoretically? what Quantum Mechanics tells us about such a possibility? To test this assumption we need tools enabling electron count in defined spatial areas. The loge theory of Raymond Daudel [39-44] provided a first attempt to falsify the Lewis and VSEPR hypotheses. The practical determination of the loges, i.e. non-overlapping domains maximizing the probability of finding given numbers of electron within them, is achieved at the price a huge numerical complexity which hampers the applicability of the method. A variant of this idea has been proposed by Andreas Savin with the concept of maximum probability domains which are not required to be non-overlapping [45-48].

For any non-overlapping partition we can measure the number of electron in each domain. If we are working in the context of quantum mechanics, we have to define a population operator for this purpose which is an easy task, since it had been already done by Diner and Claverie forty years ago [49]. In any domain, the result of an individual measure is and integer in the $[0, N]$ range, $N$ being the total number of electron with the constraint that the sum of these measures over all domain is $N$. The population of a domain, $\bar{N}$, is given by the integral of the density, it has to be understood the average of these measures. The dispersion of the measures is accounted for by the variance (the square of the standard deviation, in other words of the absolute error) for which exist an operator also given by Diner and Claverie. In fact what we are looking for are domains which minimize the variance of their populations. Tests on atoms show that the minimization of the variance fairly accounts for the shell structure of atoms $[50,51]$ and therefore confirm Lewis's first and second postulates. The analysis of the gradient vector field of the Electron Localization Function (ELF) [52] provides a partition of the molecular space into basins of attractors which correspond to cores, lone pairs and bond regions [53, 54]. As noted by Gillespie and Robinson: "This function (ELF) exhibits maxima at the most probable positions of localized electron pairs and each maximum is surrounded by a basin in which there is an increased probability of finding an electron pair. These basins correspond to the qualitative electron pair domains of the VSEPR model and have the same geometry as the VSEPR domains" [55]. It was recently shown on H-bond complexes that the ELF yields a minimal variance of the population of the moieties [56].

The ELF approach of the chemical bonding as well as the Quantum Theory of Atoms in Molecules (QTAIM) [57-59] are rigorous and efficient tools enabling qualitative and quantitative analyses of charge distributions and nothing more. They do not give any chemical or quantum chemical explanations of the bonding in molecules and solids, but instead the pieces of information which corroborate or falsify such explanations. These methods are descriptive not predictive and therefore they are not actual theories. However, they have a significant heuristic value. For example our experience of the ELF led us to introduce the concept of synaptic order of a valence basin $[60,61]$ which is defined as the number of atomic valence shell to which this basin participates. In Lewis's theory, the synaptic order is one for the non-bonding pairs and two for the bonding ones. Values larger than two enable to account for multicentre bonds and particularly for interstitial multicentre partial bond representation of bulk metals [62-64]. 


\section{Compliance with ethical standards}

Ethical stantards This text meets the requirements of the ethical stantards.

\section{References}

1. Del Re G (2003) Reaction mechanisms and chemical explanation. Ann New York Acad Sci 988:133-140

2. Thom R (1983) Paraboles et Catastrophes Flammarion, Paris

3. Hempel CG, Oppenheim P (1948) Studies in the logic of explanation. Philos Sci 15:135-175

4. Friedman M (1974) Explanation and scientific understanding. J Philos 71:5-19

5. Kitcher P (1981) Explanatory unification. Philos Sci 48:507-531

6. Salmon W (1984) Explanation and the causal structure of the world. Princeton University Press, Princeton

7. Coulson CA (1952) Valence Clarendon, Oxford

8. Scerri ER (2000) Philosophy of chemistrys-a new interdisciplinary field? J Chem Educ 77:522

9. Heelan PA (2003) Paradoxes of measurement. Ann NY Acad Sci 988:114-127

10. Pastoors A, Lenssen-Erz T, Ciqae T, Kxunta U, Thao T, Bégouën R, Biesele M, Clottes J (2015) Tracking in caves-experience based reading of pleistocene human footprints in French caves. Camb Archaeol J 25:551-564

11. Lewis GN (1926) The anatomy of science. Yale University Press, New Haven

12. Laming R (1845) Observations on a paper by Prof. Faraday concerning electric conduction and the nature of matter. Philos Mag Ser 27:420-423

13. Stoney GJ (1881) On the physical units of nature. Philos Mag 11:381-391

14. Bonchev D, Rouvray R (1999) Intuitive chemical topology concepts. Chemical topology: introduction and fundamentals. Gordon and Breach, Reading

15. Thomson JJ (1897) Cathode rays. Philos Mag 44:293-316

16. Rutherford E (1911) The scattering of $\alpha$ and $\beta$ particles by matter and the structure of the atom. Philos Mag Sci 21:669-688

17. Thomson JJ (1907) The corpuscular theory of matter. Charles Scribner's Sons, New York

18. Stark J (1915) Prinzipien der Atomdynamik, Teil III: Die elektrizität im chemischen atom S. Hirzel, Leipzig

19. Lewis GN (1916) The atom and the molecule. J Am Chem Soc 38:762-786

20. Guerlach W, Stern O (1922) Der experimentelle Nachweis des magnetischen Moments des Silberatoms. Z Phys 8:110-111

21. Guerlach W, Stern O (1922) Der experimentelle Nachweis der Richtungsquantelung im Magnetfeld. Z Phys 9:349-352

22. Guerlach W, Stern O (1922) Das magnetische Moment des Silberatoms. Z Phys 9:353-355

23. Uhlenbeck GE, Goudsmit S (1926) Spinning Electrons and the Structure of Spectra. Nature 117:264-265

24. Pauli W (1925) Über den Zusammenhang des Abschlusses der Elektronengruppen im Atom mit der Komplexstruktur der Spektren. Z Phys 31:765-783

25. Ingold CK (1922) The structure of the benzene nucleus. Part I: intranuclear tautomerism. J Chem Soc 121:1133-1143

26. Ingold CK (1933) Significance of tautomerism and of the reactions of aromatic compounds in the electronic theory of organic reactions. J Chem Soc 143:1120-1127

27. Langmuir I (1921) Types of valence. Science 54:59-67
28. Sidgwick NV (1923) LXXXV.-Co-ordination compounds and the Bohr atom. J Chem Soc Trans 123:725-730

29. Bury CR (1921) Langmuir's theory of the arrangement of electrons in atoms and molecules. J Am Chem Soc 43:1602-1609

30. Blanchard AA, Gilliland WL (1926) The constitution of nickel carbonyl and the nature of secondary valence. J Am Chem Soc 48:872-882

31. Linnett JW (1961) A Modification of the Lewis-Langmuir Octet Rule J Am Chem Soc 83:2643-2653

32. Linnett JW (1964) The electronic structure of molecules. A new approach. Methuen, London

33. Sidgwick NV, Powell HM (1940) Bakerian lecture. Stereochemical types and valency groups. Proc R Soc A 176:153-180

34. Gillespie RJ, Nyholm RS (1957) Inorganic stereochemistry. Q Rev Chem Soc 11:339-380

35. Gillespie RJ (1972) Molecular geometry. Van Nostrand Reinhold, London

36. Gillespie RJ (1991) The VSEPR model revisited. Chem Soc Rev 21:59-69

37. Gillespie RJ, Robinson EA (1996) Electron domains and the VSEPR model of molecular geometry. Angew Chem Int Ed Engl 35:495-514

38. Nelson PG (2015) A modern version of Lewis's theory of valency. Found Chem 17:153-162

39. Daudel R (1953) Sur la localisabilité des corpuscules dans les noyaux et les cortèges électroniques des atomes et des molécules. Compt Rend Acad Sci 237:601-603

40. Daudel R, Brion H, Odiot S (1955) Localizability of electrons in atoms and molecules-application to the study of the notion of shell and of the nature of chemical bonds. J Chem Phys 23:2080-2083

41. Daudel R, Odiot S, Brion H (1954) Théorie de la localisabilité des corpuscules.1 La notion de loge et la signification géometrique de la notion de couche dans le cortège électronique des atomes. J Chem Phys 51:74-77

42. Aslangul C, Constanciel R, Daudel R (1972) Aspects of the localizability of electrons and molecules: loge theory and related methods. In: Löwdin Po (ed) Advances in quantum chemistry, vol 6. Academic Press, New York, pp 93-141

43. Aslangul C, Constanciel R, Daudel R, Esnault L, Ludeña EV (1974) The loge theory as a starting point for variational calculations. I general formalism. Int J Quant Chem 8:499-522

44. Bader RFW (1975) Comparison of loge and virial methods of partitioning molecular charge distributions in Chalvet O. In: Daudel R, Diner S, Malrieu JP (eds) Localization and delocalization in quantum chemistry, vol I. Reidel, Dordrecht, pp 15-38

45. Gallegos A, Carbó-Dorca R, Lodier F, Cancès E, Savin A (2005) Maximal probability domains in linear molecules. J Comput Chem 26:455-460

46. Scemama A, Caffarel M, Savin A (2007) Maximum probability domains from quantum Monte Carlo calculations. J Comput Chem 28:442

47. Lopes OM, Braïda B, Causà M, Savin A (2012) Advances in the theory of quantum systems in chemistry and physics chap. Understanding maximum probability domains with simple models. Springer, Netherlands, pp 173-184

48. Menéndez M, Martín Pendás A, Braïda B, Savin A (2015) A view of covalent and ionic bonding from maximum probability domains. Comput Theor Chem 1053:142-149

49. Diner S, Claverie P (1976) Statistical and stochastic aspects of the delocalization problem in quantum mechanics in Chalvet $O$. In: Daudel R, Diner S, Malrieu JP (eds) Localization and delocalization in quantum chemistry, vol II. Reidel, Dordrecht, pp 395-448

50. Silvi B, Fourré I, Alikhani E (2005) The topological analysis of the electron localization function: a key for a position space representation of chemical bonds Monatshefte für. Chemie $136: 855-879$ 
51. Mingos PDM (2016) The relevance of the ELF topological approach to the Lewis, Kossel, and Langmuir bond model. The chemical bond -100 years old and getting stronger. Springer, Berlin, pp 213-247

52. Becke AD, Edgecombe KE (1990) A simple mesure of electron localization in atomic and molecular systems. J Chem Phys 92:5397-5403

53. Silvi B, Savin A (1994) Classification of chemical bonds based on topological analysis of electron localization function. Nature 371:683-686

54. Häussermann U, Wengert S, Nesper R (1994) Localization of electrons in intermetallic phases containing aluminium. Angew Chem Int Ed Engl 33:2069-2072

55. Gillespie RJ, Robinson EA (2007) Models of molecular geometry. J Comput Chem 28:87-97

56. Silvi B, Ratajczak H (2016) Hydrogen bonding and delocalization in the ELF analysis approach. Phys Chem ChemPhys $18: 27442-27449$
57. Bader RFW, Nguyen-Dang TT (1981) Quantum theory of atoms in molecules-dalton revisited in advances in quantum chemistry. Academic Press, New York, pp 63-124

58. Bader RFW (1985) Atoms in molecules. Acc Chem Res 18:9-15

59. Bader RFW (1990) Atoms in molecules: a quantum theory. Oxford University Press, Oxford

60. Krokidis X, Noury S, Silvi B (1997) Characterization of elementary chemical processes by Catastrophe theory. J Phys Chem A 101:7277-7282

61. Silvi B (2002) The synaptic order: a key concept to understand multicenter bonding. J Mol Struct 614:3-10

62. Silvi B, Gatti C (2000) Direct space representation of the metallic bond. J Phys Chem A 104:947-953

63. Lepetit C, Fau P, Fajerwerg K, Kahn ML, Silvi B (2017) Topological analysis of the metal-metal bond: a tutorial review. Coord Chem Rev 345:150-181

64. Silvi B (2017) Pressure effect on electron localization in solid lithium Struct Chem 0:null. doi:10.1007/s11224-017-0962-7 